\title{
Are You Risk Averse Over Other People's Money?
}

\author{
by \\ Sujoy Chakravarty, Glenn W. Harrison, Ernan E. Haruvy and E. Elisabet Rutström *
}

August 2005

\begin{abstract}
Decisions with uncertain outcomes are often made by one party in settings where another party bears the consequences. Whenever an agent is delegated to make decisions that affect others, such as in the typical corporate structure, does the agent make decisions that reflect the risk preferences of the principal? We examine this question in the simplest possible setting using controlled laboratory experiments. We find a remarkable result: when an individual makes a decision for an anonymous stranger, he tends to exhibit less risk aversion. This reduction is relative to his own preferences, and also relative to his belief about the other's preferences. This result has significant implications for the design of contracts between principals and agents.
\end{abstract}

* Economics Area, Indian Institute of Management, Ahmedabad, India (Chakravarty); Department of Economics, College of Business Administration, University of Central Florida, USA (Harrison and Rutström), and Department of Marketing, School of Management, University of Texas - Dallas (Haruvy). E-mail contacts: SUJOY@IIMAHD.ERNET.IN, GHARRISON@RESEARCH.BUS.UCF.EDU, EHARUVY@UTDALLAS.EDU, and ERUTSTROM@BUS.UCF.EDU. Chakravarty thanks the Indian Institute of Management for research support under Seed Money Grant \#1105481. Rutström thanks the U.S. National Science Foundation for research support under grants NSF/IIS 9817518 and NSF/POWRE 9973669. Supporting data, statistical code and experimental instructions are stored in the ExLab Digital Archive at http://exlab.bus.ucf.edu. 
Decisions with uncertain outcomes are often made by one party in settings where another party bears the consequences. Whenever an agent is delegated to make decisions that affect others, such as in the typical corporate structure, does the agent make decisions that reflect the risk

preferences of the party bearing the consequences? In the principal-agent literature, if a principal and his agent do not have the same risk attitude, efficiency loss could result (e.g., Kreps [1990; p. 582/3] and Grossman and Hart [1983]).

We examine the risk attitudes of principals and their agents in the simplest possible setting using controlled laboratory experiments. We find a remarkable result: agents tend to be significantly less risk averse when they make decisions over another person's money, compared to decisions that they make over their own money. Both sets of decisions reflect risk aversion, but when people are asked to make decisions for others, they make decisions consistent with lower risk aversion. This is despite the fact that beliefs regarding the other person's preferences appear to be unbiased. This result has significant implications for the analysis of behavior between principals and agents.

In section 1 we explain the experiment we developed to identify differences in the risk preferences of principals and agents. In section 2 we review procedures, and in section 3 examine the results. We draw conclusions in section 4.

\section{Experimental Design}

We employ an experimental measure for risk aversion called a multiple price list, previously used by Holt and Laury [2002] and Harrison, Johnson, McInnes and Rutström [2005]. Each subject is presented with a choice between two lotteries, which we call A or B. Table 1 illustrates the basic payoff matrix presented to subjects. The first row shows that lottery A offered a $10 \%$ chance of receiving 400 Indian Rupees (Rs) and a 90\% chance of receiving Rs 500. The expected value of this lottery, $\mathrm{EV}^{\mathrm{A}}$, is shown in the third-last column as Rs 490, although the $\mathrm{EV}$ columns were not presented to subjects. Similarly, lottery B in the first row has chances of payoffs of Rs 960 and Rs 25 , for an expected value of Rs 118 . Thus the two lotteries have a relatively large difference in expected values, in this case Rs 372. As one proceeds down the matrix, the expected value of both 
lotteries increases, but the expected value of lottery B becomes greater than the expected value of lottery A.

The subject chooses A or B in each row, and one row is later selected at random for payout for that subject. The logic behind this test for risk aversion is that only risk-loving subjects would take lottery B in the first row, and only risk-averse subjects would take lottery A in the second last row. Assuming local non-satiation, the last row is simply a test that the subject understood the instructions, and has no relevance for risk aversion at all. Most subjects would be expected to switch from $\mathrm{A}$ to $\mathrm{B}$ on some row in the table, and this switching point can then be used to infer their risk attitude. A risk neutral subject should switch from choosing A to B when the EV of each is about the same, so a risk-neutral subject would choose A for the first four rows and B thereafter.

All subjects came to one room initially, where they were seated and received a randomly distributed instruction packet colored red or yellow. The instruction packet was initially sealed, so that subjects picked their color at random. They were presented with some general instructions, including an explanation of the role of a monitor who would ensure that all instructions and information were actually applied. The monitor was chosen at random from the subjects. Half of the subjects (those with red instruction packets) were then taken to another room, and a separate experimenter conducted the instructions in each room. The substantive task instructions were handed out sequentially: when performing the first task, subjects had no information about the nature of the subsequent tasks.

In the first room subjects were asked to make choices about the lotteries, and in the other room the subjects were told that they had no choices to make, but that they would receive the consequences of some choices made in the other room. In the first room, where the choices were made, subjects proceeded in one of two orders. Either they made decisions over their own money first, and then decisions over another person's money, or vice versa. Thus we control for order effects, while obtaining in-sample responses. The subjects in the first room were told that they had been paired with one other person in the second room, but that they would never know each other's identity. The monitor verified the information provided in instructions in each room. All random 
draws were resolved using a physical device, a simple 10 -sided die. ${ }^{1}$

In addition, and after the risk aversion choices had been made, each subject in the first room was asked to state the number of choices of lottery A that they believed the rest of the people in the room would make. They were asked to state their belief for each of the treatments, where beliefs and actual averages were rounded to the nearest integer. This belief was elicited under simple incentives. ${ }^{2}$ The purpose of this additional task was to find out what risk attitudes each subject thought other people, drawn at random from the same population, would have. If the subject thought that everyone else was less risk averse than they were, they might choose a less risk averse outcome for the other person in the belief that they were selecting as they would. These data provide some check on hypotheses of this kind.

\section{Procedures}

The payoffs are in Indian Rupees, since the experiments were conducted in India. At the time of the experiment (June 2005) the official exchange rate was 1 U.S. dollar $=$ Rs 44.8, implying prizes worth $\$ 8.90$ and $\$ 11.12$ in the "safe lottery" A, and worth $\$ 21.41$ and $\$ 0.56$ in the "risky lottery" B. These are approximately 5.5 times the baselines prizes offered in the experiments of Holt and Laury [2002]. However, India's official exchange rate does not properly reflect the purchasing power of the Rupee in India, in terms of goods and services. Using purchasing power data for 2000 from the Penn World Tables of Heston, Summers and Aten [2002], our payoffs can instead be calculated as $\$ 65, \$ 52, \$ 125$ and $\$ 3.25$, respectively, for a scaling of 32.5 times the baselines prizes of Holt and Laury [2002]. ${ }^{3}$ The conversion to US dollars at official exchange rates or purchasing power rates does not, of course, affect the inferences about risk-loving or risk aversion from observed choices.

\footnotetext{
${ }^{1}$ The complete instructions are available in an Appendix, or at http://exlab.bus.ucf.edu.

${ }^{2}$ If the estimate was exactly correct in one of the two treatments, they would receive Rs 25; if the estimates were exactly correct in both treatments they would receive Rs 50; if it was 1 off, on either side, they would receive Rs 10 for that column; if it was 1 off in both treatments, they would receive Rs 10 for each treatment; and if it was more than 1 off in both treatments they would not receive anything from this task.

${ }^{3}$ The official exchange rate in 2000 was very close to the rate prevailing in mid-2005.
} 
We recruited 74 subjects from classes at the Indian Institute of Management (IIM) in Ahmedabad, India. This is the premier Business School in India, and entrance depends on the result of a grueling competitive exam and personal interview. ${ }^{4}$ Although influenced by the salaries of several super-star graduates that are hired directly into multinational corporations overseas, the average starting salaries for graduates in 2003 (2004) was Rs 5.88 (7.1) lakhs per annum, where a lakh is Rs 100,000. This converts to roughly USD 13,125 (USD 15,548) at official exchange rates, but USD 76,662 (USD 92,568) using purchasing power rates. Teaching assistants at the IIM in Ahmedabad received average annual salaries in 2005 of Rs 96,000 (USD 2,143), which converts to roughly Rs 50 per hour. So our payoffs are definitely in the range that will be viewed as significant by these subjects.

Subjects were generally representative of the student population at IIM in Ahmedabad in terms of family income levels (moderate to high, by average Indian standards), sex (predominantly male), ethnicity (predominantly Hindu) and undergraduate major (engineering and computer sciences). We asked each subject to complete a questionnaire eliciting information on individual characteristics, and condition our statistical analysis on those differences as appropriate.

All subjects were paid in cash at the end of the session. In addition to earnings, each subject received Rs 25 for turning up as agreed.

\section{Results}

Figure 1 displays the main results from the experiment. On the bottom axis we list each problem, corresponding to the rows in Table 1. The vertical axis shows the fraction of choices of the safe lottery, option A. The dashed line displays what a risk neutral subject would do: pick the safe lottery A until the EV of the risky lottery B is greater than the EV of lottery A, and then pick lottery B. The other lines show the observed responses, pooled over the task order, which we control for in a formal statistical analysis below. Subjects that pick the safe option more than the risk

\footnotetext{
${ }^{4}$ The web site of the Institute, http://www.iimahd.ernet.in/ provides more information.
} 
neutral prediction are risk averse, as discussed earlier. We will refer to the treatment where subjects make decisions about their own money as "Own Attitude," and to the treatment where subjects make decisions about other people’s money as “Advice.” So we see evidence that subjects are risk averse in "Own Attitude," but are less risk averse in "Advice." Of course, these lines only reflect averages, and there is typically more noise around the "middle" of these pictures, so this conclusion must await a more formal statistical analysis. However, the average number of safe choices were 6.35 and 5.03 in the "Own Attitude" and "Advice" treatments, respectively. This difference is statistically significant at any conventional level using parametric $t$-tests and non-parametric Wilcoxon SignedRank tests.

We examine the data using a constant relative risk aversion (CRRA) characterization. Specifically, we assume that utility is defined as $\mathrm{U}(\mathrm{y})=\left(\mathrm{y}^{1-r}\right) /(1-r)$, where $r$ is the CRRA coefficient and $\mathrm{r} \neq 1$. With this parameterization, $r=0$ denotes risk neutral behavior, $r>0$ denotes risk aversion, and $r<0$ denotes risk loving. The dependent variable is the binary choice between lottery A and $\mathrm{B}$, and a standard probit function links the difference in expected utility (conditional on a candidate value of $r$ ) to the observed binary choices. Each "switch point" in Table 1 implies that the subject has a CRRA coefficient $r$ within a well-defined interval, such as shown in Holt and Laury [2002; Table 3, p.1649]. For example, risk neutral subjects would have switched from lottery A to lottery B at row 5, implying that their CRRA coefficient $r$ lies between -0.15 and +0.15 . Since each subject provided multiple observations there are corrections for the possible correlation of errors associated with a given subject. ${ }^{5}$

Table 2 displays the results of a formal statistical test. The estimates presented here are a

\footnotetext{
5 The use of clustering to allow for "panel effects" from unobserved individual effects is common in the statistical survey literature. Clustering commonly arises in national field surveys from the fact that physically proximate households are often sampled to save time and money, but it can also arise from more homely sampling procedures. For example, Williams [2000; p.645] notes that it could arise from dental studies that "collect data on each tooth surface for each of several teeth from a set of patients" or "repeated measurements or recurrent events observed on the same person." The procedures for allowing for clustering allow heteroskedasticity between and within clusters, as well as autocorrelation within clusters. They are closely related to the "generalized estimating equations" approach to panel estimation in epidemiology (see Liang and Zeger [1986]), and generalize the "robust standard errors" approach popular in econometrics (see Rogers [1993]). Wooldridge [2003] reviews some issues in the use of clustering for panel effects, in particular noting that significant inferential problems may arise with small numbers of panels.
} 
linear function of the CRRA coefficient $r$. The most important result is the estimate for the binary dummy (advice) picking out the risk aversion responses over other people's money. It shows that RRA is 0.32 lower when making decisions over other people's money, and that this effect is statistically significant with a $p$-value less than 0.001 . There does not appear to be a significant effect from task order, sex or age. But the educational levels of parents does matter, as does income levels.

How do we know that this shift is not an attempt to pick risk attitudes that match those of the people they will be applied to? This is the role of our additional task, where we elicited beliefs about the average responses of others in the room. The results indicate that risk attitudes about one's own money and beliefs about the own risk aversion of others are virtually the same. The average number of safe choices observed were 6.35 and 5.95, respectively for Own Attitudes and Beliefs about Others Own Attitudes, which is not significant using a two-sided $t$-test $(p$-value $=$ 0.13), a Wilcoxon Signed-Rank test $(p$-value $=0.26)$, or a Sign test $(p$-value $=0.52)$. Thus the differences observed in Figure 1 and Table 3 are not due to subjects having beliefs that their risk attitudes were un-representative on average.

\section{Conclusions}

We find that individuals are generally risk averse for the domain of income represented in our experiments. They are less risk averse when making decisions over other people's money, and this effect is statistically significant. The difference does not appear to be driven by an attempt to pick risk attitudes that reflect the risk attitudes of others.

A related observation in the literature is that when risky decisions are hypothetical, lower risk aversion is observed. There is extensive evidence, presented in Holt and Laury [2002][2005] and Harrison [2005], that measures of risk aversion in hypothetical choices indicate significantly lower risk aversion than choices that entail real consequences. Indeed, the qualitative pattern matches ours: Subjects are moderately risk averse over their own money, and less risk averse when the decisions have no monetary consequences for them. The similarity between the results suggests that the underlying explanation might be similar. One explanation that would fit both hypothetical choices 
and choices for others is an objective function that includes other values than just consumption values (or money). Perhaps the subjects felt more "socially visible" when making decisions for someone else, despite the anonymity we imposed, and values derived from social approval or social norms affected their decisions.

Yet another explanation that builds on the social dimension of the decision over other people's money involves subjects exhibiting some form of "social preference" in their decisions. We know from our follow-up questions about the choices of others that this is not because they believed that others were less risk averse than they were. However, it is entirely possible that they were viewing this as a social risk decision, and employing different preferences over social risk than they do over individual risk. Direct tests of this hypothesis in group tasks by Harrison, Lau, Rutström and Tarazona-Gómez [2005] find that social risk preferences for a group in which one is a member are virtually identical to individual risk preferences. The main difference between those settings and ours is that here the individual is completely removed from the consequences to his or her decision.

Finally, at a more speculative level, if risk preferences over other people's money differ quantitatively from risk preferences over one's own money, perhaps the decision processes associated with risk preferences differ qualitatively. Thus, it could be that some of the alleged anomalies associated with ill-behaved risk preferences, such as those presented in Rabin and Thaler [2001], are mitigated when one considers decisions over other people's money. 
Table 1: Payoff Table for Risk Aversion Experiments

All currency units are Indian Rupees (Rs). At the time of the experiment 1 USD $=44.8$ Rs using the official exchange rate.

\begin{tabular}{|c|c|c|c|c|c|c|c|c|c|c|}
\hline \multicolumn{4}{|c|}{ Lottery A } & \multicolumn{4}{|c|}{ Lottery B } & \multirow{2}{*}{$\mathrm{EV}^{\mathrm{A}}$} & \multirow{2}{*}{$E V^{\mathrm{B}}$} & \multirow{2}{*}{ Difference } \\
\hline $\mathrm{p}(400)$ & & $\mathrm{p}(500)$ & & $\mathrm{p}(960)$ & & $\mathrm{p}(25)$ & & & & \\
\hline 0.1 & 400 & 0.9 & 500 & 0.1 & 960 & 0.9 & 25 & 490 & 118.5 & 372 \\
\hline 0.2 & 400 & 0.8 & 500 & 0.2 & 960 & 0.8 & 25 & 480 & 212 & 268 \\
\hline 0.3 & 400 & 0.7 & 500 & 0.3 & 960 & 0.7 & 25 & 470 & 305.5 & 164.5 \\
\hline 0.4 & 400 & 0.6 & 500 & 0.4 & 960 & 0.6 & 25 & 460 & 399 & 61 \\
\hline 0.5 & 400 & 0.5 & 500 & 0.5 & 960 & 0.5 & 25 & 450 & 492.5 & -42.5 \\
\hline 0.6 & 400 & 0.4 & 500 & 0.6 & 960 & 0.4 & 25 & 440 & 586 & -146 \\
\hline 0.7 & 400 & 0.3 & 500 & 0.7 & 960 & 0.3 & 25 & 430 & 679.5 & -249.5 \\
\hline 0.8 & 400 & 0.2 & 500 & 0.8 & 960 & 0.2 & 25 & 420 & 773 & -353 \\
\hline 0.9 & 400 & 0.1 & 500 & 0.9 & 960 & 0.1 & 25 & 410 & 866.5 & -456.5 \\
\hline 1 & 400 & 0 & 500 & 1 & 960 & 0 & 25 & 400 & 960 & -560 \\
\hline
\end{tabular}

Note: The last three columns in this table, showing the expected values of the lotteries, were not shown to subjects. 
Figure 1: Advising Others About Risk

Fraction choosing safe option A in each choice problem

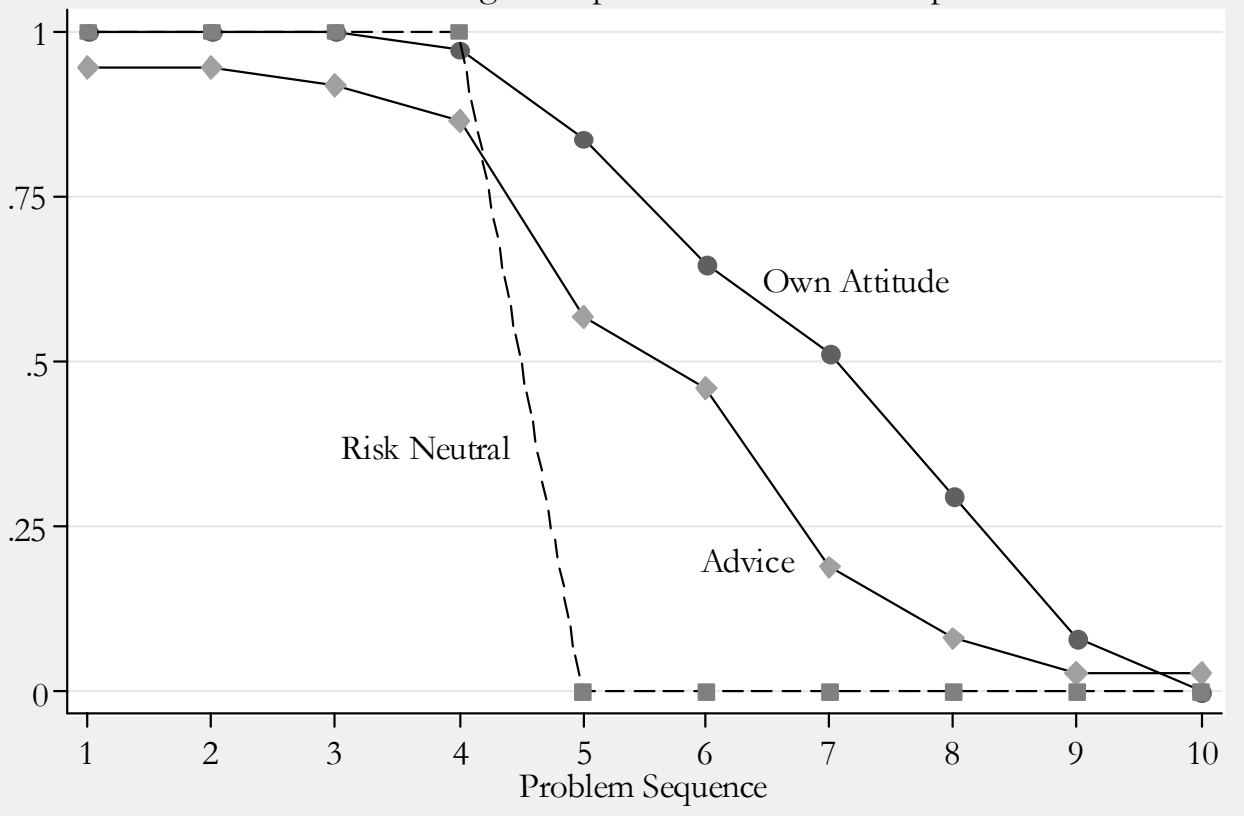

Table 2: Statistical Model of Risk Aversion Responses

Maximum-likelihood estimates of CRRA utility function. $\mathrm{N}=740$ binary choices by 37 subjects in two MPL tasks. Estimates corrected for clustering on the individual.

Coefficient estimates for $r$.

\begin{tabular}{|c|c|c|c|c|c|c|}
\hline Variable & Description & Estimate & $\begin{array}{c}\text { Standard } \\
\text { Error }\end{array}$ & $p$-value & $\begin{array}{c}\text { Lower } 95 \% \\
\text { Confidence } \\
\text { Interval }\end{array}$ & $\begin{array}{c}\text { Upper 95\% } \\
\text { Confidence } \\
\text { Interval }\end{array}$ \\
\hline Constant & & 0.581 & 0.280 & 0.038 & 0.032 & 1.130 \\
\hline advice & Advice Responses & -0.320 & 0.081 & 0.000 & -0.479 & -0.162 \\
\hline Order & Advice comes first & 0.046 & 0.148 & 0.753 & -0.243 & 0.336 \\
\hline Male & Male & 0.079 & 0.208 & 0.705 & -0.329 & 0.487 \\
\hline Over22 & Years over 22 in age & 0.009 & 0.047 & 0.843 & -0.083 & 0.102 \\
\hline ParentsEd & Some post-grad education of parents & -0.274 & 0.143 & 0.055 & -0.553 & 0.006 \\
\hline IncMed & Parents earned between 2.5 and 7.5 lakhs & 0.412 & 0.198 & 0.038 & 0.023 & 0.801 \\
\hline IncHigh & Parents earned more than 7.5 lakhs & 0.269 & 0.205 & 0.188 & -0.132 & 0.670 \\
\hline Smoker & Current smoker & -0.174 & 0.169 & 0.303 & -0.506 & 0.157 \\
\hline
\end{tabular}

Note: Wald test for the null hypothesis that all coefficients are zero has a $\chi_{8}^{2}$ value of 32.9 , implying a $p$-value $<0.001$. 


\section{References}

Grossman, Sanford J., and Hart, Oliver D., "An Analysis of the Principal-Agent Problem," Econometrica, 51(1), January 1983, 7-46.

Harrison, Glenn W., "Hypothetical Bias Over Uncertain Outcomes,” Working Paper 05-04, Department of Economics, College of Business Administration, University of Central Florida, 2005; forthcoming in J.A. List (ed)., Using Experimental Methods in Environmental and Resource Economics (Northampton, MA: Elgar, 2005).

Harrison, Glenn W.; Johnson, Eric; McInnes, Melayne M., and Rutström, E. Elisabet, "Risk Aversion and Incentive Effects: Comment," American Economic Review, 95(3), June 2005, 897901.

Harrison, Glenn W., Lau, Morten I., Rutström, E. Elisabet, and Tarazona-Gómez, Marcela "Preferences Over Social Risk," Working Paper 05-06, Department of Economics, College of Business Administration, University of Central Florida, 2005.

Heston, Alan ; Summers, Robert, and Aten, Bettina, Penn World Table Version 6.1, Center for International Comparisons, University of Pennsylvania (CICUP), October 2002; available at http://pwt.econ.upenn.edu/php_site/pwt_index.php

Holt, Charles A., and Laury, Susan K., "Risk Aversion and Incentive Effects," American Economic Review, 92(5), December 2002, 1644-1655.

Holt, Charles A., and Laury, Susan K., "Risk Aversion and Incentive Effects: New Data Without Order Effects," American Economic Review, 95(3), June 2005, 902-912.

Kreps, David M., A Course in Microeconomic Theory (Princeton, NJ: Princeton University Press, 1990).

Liang, K-Y., and Zeger, S.L., "Longitudinal Data Analysis Using Generalized Linear Models," Biometrika, 73, 1986, 13-22.

Rabin, Matthew and Thaler, Richard, "Anomalies: Risk Aversion,” Journal of Economic Perspectives, 15, Winter 2001, 219-232.

Rogers, W. H., "Regression Standard Errors in Clustered Samples," Stata Technical Bulletin, 13, 1993, $19-23$.

Williams, Rick L., “A Note on Robust Variance Estimation for Cluster-Correlated Data,” Biometrics, 56, June 2000, 645-646.

Wooldridge, Jeffrey, "Cluster-Sample Methods in Applied Econometrics," American Economic Review (Papers \& Proceedings), 93, May 1993, 133-138. 
Appendix: Experimental Instructions (NOT FOR PUBLICATION)

\section{WELCOME TO THE RESEARCH STUDY DESCRIPTION}

This is a study of economic decision making. We think you will find it interesting, you will be paid 25 Rupees for your participation and you could earn additional money. How much you earn will depend partly on chance. For some of you, earnings will also be based partly on the choice you make in decision problems which you will be presented with. For the rest of you earnings will be based partly on the choice made by another participant. The instructions are simple and you will benefit from following them carefully.

The problems are not designed to test you. What we want to know is what choices you would make in them. The only right answer is what you really would choose. That is why the problems give you the chance of earning real money. You will be paid in cash today, at the end of the session.

The tasks will proceed in several short parts.

Three of the parts are short decision problems in which chance may play a part. Each decision problem requires some of you to make a choice. This is described in more detail in a moment. All three of these parts may result in additional earnings over and above the 25 Rupees participation fee.

The remaining parts consist of a few questions about you. This information is for research use only. The published results of our research will not identify you, or the choice you made in any way. Nor will we give this identifying information to anyone else. In fact, we will only identify you on these sheets by a numeric ID, and that ID will not appear on the sheet that has your name for our payment records.

We expect the entire task to take less than 60 minutes. You are free to leave at any time, but if you do not complete all tasks you will not receive the participation fee or your earnings. 
ID:

\section{INSTRUCTIONS}

At this stage we will split everyone into two groups. Some of you will be going to a different room, and some of you will be staying here. Please do not talk as we move between rooms. As you may have noticed, the instruction pages you received in the envelope you selected are either red or yellow.

Those with a red sheet should come now with my assistant, who will take you into a room next door. The rest of you, with yellow sheets, will stay here. Before we separate into different rooms we will select one of you as a monitor who will go between the rooms and verify to the other participants that the descriptions of what happens in the other room are accurate. The monitor will be paid a fixed fee for doing this, with no relation to the earnings from the tasks. One of you has a sheet inside your instruction package that says "You are the Monitor." Please identify yourself at this point.

We will now read out the instructions for the monitor.

You have been randomly selected to be the monitor in this experiment. Instead of receiving earnings from the task, you will be paid a fixed fee for being the monitor. We will tell you later how much this fee is. You will simply be asked to visit both of the rooms in which the experiment is conducted to listen to the instructions read out there, and to verify to the other room that what is being said is in fact accurate. When visiting a room, you should ask any questions you need to in order to perform this job well. Nevertheless, you may not in any way identify any of the people in the room to each other. You will also not be able to see any of the decisions made.

After the decisions have been made, the decision sheets will be put into an envelope, which is then closed. You will then accompany an experimenter to the other room to deliver them there, but you will not see the content of them. Do you have any questions about what you are to do?

We now ask all of you who have red sheets in your instruction package to accompany my assistant. 
Your decision sheet shows ten decisions listed on the left. Each decision is a paired choice between "Option A" and "Option B." You will make a choice on each row and record these in the final column. Your decisions will determine your payoffs from this decision task.

Here is a ten-sided die that will be used to determine payoffs. The faces are numbered from 0 to 9 , and we will use the 0 face of the die to serve as 10 . Look at Decision 1 at the top. Option A pays 400 Rupees if the throw of the ten sided die is 1 , and it pays 500 Rupees if the throw is $2-10$. Option B yields 960 Rupees if the throw of the die is 1 , and it pays 25 Rupees if the throw is $2-10$.

The other Decisions are similar, except that as you move down the table, the chances of the higher payoff for each option increase. In fact, for Decision 10 in the bottom row, the die will not be needed since each option pays the highest payoff for sure, so your choice here is between 400 Rupees or 960 Rupees.

After you have made all of your choices, you will throw this die twice, once to select one of the ten decisions to be used, and a second time to determine what your payoff is for the option you chose, A or B, for the particular decision selected. Even though you will make ten decisions, only one of these will end up affecting your earnings, but you will not know in advance which decision will be used.

We will go around the room and let you perform the die rolls after you have completed the next three short tasks. We will then pay each of you in private and you will be free to go.

Please fill in the decision sheets now. Fill in the subject ID number that you can see on the yellow instruction pages you received inside the envelope. This goes in the top left corner of the decision sheet.

OVER 
ID: $\operatorname{Rr} 1$

\begin{tabular}{|c|c|c|c|c|}
\hline Decision & Option A & Option B & \multicolumn{2}{|c|}{$\begin{array}{l}\text { Your Choice } \\
\text { (Circle A or B) }\end{array}$} \\
\hline 1 & $\begin{array}{l}400 \text { if throw of die is } 1 \\
500 \text { if throw of die is } 2-10\end{array}$ & $\begin{array}{l}960 \text { if throw of die is } 1 \\
25 \text { if throw of die is } 2-10\end{array}$ & $A$ & $B$ \\
\hline 2 & $\begin{array}{l}400 \text { if throw of die is } 1-2 \\
500 \text { if throw of die is } 3-10\end{array}$ & $\begin{array}{l}960 \text { if throw of die is } 1-2 \\
25 \text { if throw of die is } 3-10\end{array}$ & $A$ & $B$ \\
\hline 3 & $\begin{array}{l}400 \text { if throw of die is } 1-3 \\
500 \text { if throw of die is } 4-10\end{array}$ & $\begin{array}{l}960 \text { if throw of die is } 1-3 \\
25 \text { if throw of die is } 4-10\end{array}$ & $A$ & $B$ \\
\hline 4 & $\begin{array}{l}400 \text { if throw of die is } 1-4 \\
500 \text { if throw of die is } 5-10\end{array}$ & $\begin{array}{l}960 \text { if throw of die is } 1-4 \\
25 \text { if throw of die is } 5-10\end{array}$ & $A$ & $B$ \\
\hline 5 & $\begin{array}{l}400 \text { if throw of die is } 1-5 \\
500 \text { if throw of die is } 6-10\end{array}$ & $\begin{array}{l}960 \text { if throw of die is } 1-5 \\
25 \text { if throw of die is } 6-10\end{array}$ & $A$ & $B$ \\
\hline 6 & $\begin{array}{l}400 \text { if throw of die is } 1-6 \\
500 \text { if throw of die is } 7-10\end{array}$ & $\begin{array}{l}960 \text { if throw of die is } 1-6 \\
25 \text { if throw of die is } 7-10\end{array}$ & $A$ & $B$ \\
\hline 7 & $\begin{array}{l}400 \text { if throw of die is } 1-7 \\
500 \text { if throw of die is } 8-10\end{array}$ & $\begin{array}{l}960 \text { if throw of die is } 1-7 \\
25 \text { if throw of die is } 8-10\end{array}$ & $A$ & $\mathrm{~B}$ \\
\hline 8 & $\begin{array}{l}400 \text { if throw of die is } 1-8 \\
500 \text { if throw of die is } 9-10\end{array}$ & $\begin{array}{l}960 \text { if throw of die is } 1-8 \\
25 \text { if throw of die is } 9-10\end{array}$ & $A$ & $B$ \\
\hline 9 & $\begin{array}{l}400 \text { if throw of die is } 1-9 \\
500 \text { if throw of die is } 10\end{array}$ & $\begin{array}{l}960 \text { if throw of die is } 1-9 \\
25 \text { if throw of die is } 10\end{array}$ & $A$ & $B$ \\
\hline 10 & 400 if throw of die is $1-10$ & 960 if throw of die is $1-10$ & $A$ & $\mathrm{~B}$ \\
\hline
\end{tabular}

DECISION ROW CHOSEN BY FIRST THROW OF THE DIE:

THROW OF THE DIE TO DETERMINE PAYMENT:

YOUR EARNINGS: 
Your decision sheet shows ten decisions listed on the left. Notice that this decision sheet is quite similar to the one you used before, although the decision you are asked to make is quite different. Each decision is a paired choice between "Option A" and "Option B", like before. You will make a choice on each row and record these in the final column. Contrary to the previous task, here your decisions will determine the payoffs to one person in the other room, picked at random. The person in this other room is not given a task at all. Apart from the participation fee of 25 Rupees, his or her earnings depend only on your decision.

To verify this we will now take the monitor to the other room. We will wait for the monitor to return before proceeding.

The monitor has now returned. We will now ask the monitor to read out the instructions given in the other room.

Are there any questions regarding the other room?

We will now perform the next task, where your decisions will determine the payoff to one of the people in the other room. You will be matched to one person in the other room, picked at random.

As we started the experiment you received your instructions packages in a random order. This ensures that the ID number that you have received, and that is listed in the top left corner of your decision sheet, was given to you randomly. You may recall that everyone who left the room received a red instruction package and everyone who remained here received yellow ones. The two sets of instructions, the red and the yellow, have matching ID numbers. Thus, there is one person in the other room who has a red instruction package with the same ID number as yours. You will be matched with this person. We will not reveal to you who this person is, however, to guarantee that person's anonymity. This is the person whose payoffs depend on your decisions. 
Here is a ten-sided die that will be used to determine payoffs. The faces are numbered from 0 to 9 , and we will use the 0 face of the die to serve as 10 . Look at Decision 1 at the top. Option A pays 400 Rupees if the throw of the ten sided die is 1 , and it pays 500 Rupees if the throw is $2-10$. Option B yields 960 Rupees if the throw of the die is 1 , and it pays 25 Rupees if the throw is $2-10$.

The other Decisions are similar, except that as you move down the table, the chances of the higher payoff for each option increase. In fact, for Decision 10 in the bottom row, the die will not be needed since each option pays the highest payoff for sure, so your choice here is between 400 Rupees or 960 Rupees.

After you have made all of your choices, you will throw this die twice, once to select one of the ten decisions to be used, and a second time to determine what the payoff is for the option you chose, A or B, for the particular decision selected. Even though you will make ten decisions, only one of these will end up affecting the earnings of the other person, but you will not know in advance which decision will be used.

When you are finished, we will come around and hand out the instructions for the final task. After that we will let you perform the die rolls. We will then pay each of you in private and you will be free to go.

After you have finished filling in the decision sheet, please write your ID number on the outside of the envelope.

Please fill in the decision sheets now. Fill in the subject ID number that you can see on the yellow instruction pages you received inside the envelope. This goes in the top left corner of the decision sheet. 
ID: $\operatorname{Rr} 3$

\begin{tabular}{|c|c|c|c|c|}
\hline Decision & Option A & Option B & \multicolumn{2}{|c|}{$\begin{array}{l}\text { Your Choice } \\
\text { (Circle A or B) }\end{array}$} \\
\hline 1 & $\begin{array}{l}400 \text { if throw of die is } 1 \\
500 \text { if throw of die is } 2-10\end{array}$ & $\begin{array}{l}960 \text { if throw of die is } 1 \\
25 \text { if throw of die is } 2-10\end{array}$ & $A$ & $\mathrm{~B}$ \\
\hline 2 & $\begin{array}{l}400 \text { if throw of die is } 1-2 \\
500 \text { if throw of die is } 3-10\end{array}$ & $\begin{array}{l}960 \text { if throw of die is } 1-2 \\
25 \text { if throw of die is } 3-10\end{array}$ & $A$ & $B$ \\
\hline 3 & $\begin{array}{l}400 \text { if throw of die is } 1-3 \\
500 \text { if throw of die is } 4-10\end{array}$ & $\begin{array}{l}960 \text { if throw of die is } 1-3 \\
25 \text { if throw of die is } 4-10\end{array}$ & $A$ & $B$ \\
\hline 4 & $\begin{array}{l}400 \text { if throw of die is } 1-4 \\
500 \text { if throw of die is } 5-10\end{array}$ & $\begin{array}{l}960 \text { if throw of die is } 1-4 \\
25 \text { if throw of die is } 5-10\end{array}$ & $A$ & B \\
\hline 5 & $\begin{array}{l}400 \text { if throw of die is } 1-5 \\
500 \text { if throw of die is } 6-10\end{array}$ & $\begin{array}{l}960 \text { if throw of die is } 1-5 \\
25 \text { if throw of die is } 6-10\end{array}$ & $A$ & $B$ \\
\hline 6 & $\begin{array}{l}400 \text { if throw of die is } 1-6 \\
500 \text { if throw of die is } 7-10\end{array}$ & $\begin{array}{l}960 \text { if throw of die is } 1-6 \\
25 \text { if throw of die is } 7-10\end{array}$ & $A$ & $B$ \\
\hline 7 & $\begin{array}{l}400 \text { if throw of die is } 1-7 \\
500 \text { if throw of die is } 8-10\end{array}$ & $\begin{array}{l}960 \text { if throw of die is } 1-7 \\
25 \text { if throw of die is } 8-10\end{array}$ & A & $B$ \\
\hline 8 & $\begin{array}{l}400 \text { if throw of die is } 1-8 \\
500 \text { if throw of die is } 9-10\end{array}$ & $\begin{array}{l}960 \text { if throw of die is } 1-8 \\
25 \text { if throw of die is } 9-10\end{array}$ & $A$ & $B$ \\
\hline 9 & $\begin{array}{l}400 \text { if throw of die is } 1-9 \\
500 \text { if throw of die is } 10\end{array}$ & $\begin{array}{l}960 \text { if throw of die is } 1-9 \\
25 \text { if throw of die is } 10\end{array}$ & A & $\mathrm{B}$ \\
\hline 10 & 400 if throw of die is $1-10$ & 960 if throw of die is $1-10$ & A & $\mathrm{B}$ \\
\hline
\end{tabular}

DECISION ROW CHOSEN BY FIRST THROW OF THE DIE:

THROW OF THE DIE TO DETERMINE PAYMENT:

EARNINGS TO THE OTHER PERSON: 
Your decision sheet shows ten decisions listed on the left. Each decision is a paired choice between "Option A" and "Option B." You will make a choice on each row and record these in the final column. Your decisions will determine the payoffs from this task to one person in the other room, picked at random. The person in this other room is not given a task at all. Apart from the participation fee of 25 Rupees, his or her earnings depend only on your decision.

To verify this we will now take the monitor to the other room. We will wait for the monitor to return before proceeding.

The monitor has now returned. We will now ask the monitor to read out the instructions given in the other room.

Are there any questions regarding the other room?

We will now perform the next task, where your decisions will determine the payoff to one of the people in the other room. You will be matched to one person in the other room, picked at random.

As we started the experiment you received your instructions packages in a random order. This ensures that the ID number that you have received, and that is listed in the top left corner of your decision sheet, was given to you randomly. You may recall that everyone who left the room received a red instruction package and everyone who remained here received yellow ones. The two sets of instructions, the red and the yellow, have matching ID numbers. Thus, there is one person in the other room who has a red instruction package with the same ID number as yours. You will be matched with this person. We will not reveal to you who this person is, however, to guarantee that person's anonymity. This is the person whose payoffs depend on your decisions. 
Here is a ten-sided die that will be used to determine payoffs. The faces are numbered from 0 to 9 , and we will use the 0 face of the die to serve as 10 . Look at Decision 1 at the top. Option A pays 400 Rupees if the throw of the ten sided die is 1 , and it pays 500 Rupees if the throw is $2-10$. Option B yields 960 Rupees if the throw of the die is 1 , and it pays 25 Rupees if the throw is $2-10$.

The other Decisions are similar, except that as you move down the table, the chances of the higher payoff for each option increase. In fact, for Decision 10 in the bottom row, the die will not be needed since each option pays the highest payoff for sure, so your choice here is between 400 Rupees or 960 Rupees.

After you have made all of your choices, you will throw this die twice, once to select one of the ten decisions to be used, and a second time to determine what the payoff is for the option you chose, A or B, for the particular decision selected. Even though you will make ten decisions, only one of these will end up affecting the earnings of the other person, but you will not know in advance which decision will be used.

We will go around the room and let you perform the die rolls after you have completed the next three short tasks. We will then pay each of you in private and you will be free to go.

After you have finished filling in the decision sheet, please write your ID number on the outside of the envelope.

Please fill in the decision sheets now. Fill in the subject ID number that you can see on the yellow instruction pages you received inside the envelope. This goes in the top left corner of the decision sheet. 
ID: rR1

\begin{tabular}{|c|c|c|c|c|}
\hline Decision & Option A & Option B & \multicolumn{2}{|c|}{$\begin{array}{l}\text { Your Choice } \\
\text { (Circle A or B) }\end{array}$} \\
\hline 1 & $\begin{array}{l}400 \text { if throw of die is } 1 \\
500 \text { if throw of die is } 2-10\end{array}$ & $\begin{array}{l}960 \text { if throw of die is } 1 \\
25 \text { if throw of die is } 2-10\end{array}$ & $A$ & $\mathrm{~B}$ \\
\hline 2 & $\begin{array}{l}400 \text { if throw of die is } 1-2 \\
500 \text { if throw of die is } 3-10\end{array}$ & $\begin{array}{l}960 \text { if throw of die is } 1-2 \\
25 \text { if throw of die is } 3-10\end{array}$ & $A$ & $B$ \\
\hline 3 & $\begin{array}{l}400 \text { if throw of die is } 1-3 \\
500 \text { if throw of die is } 4-10\end{array}$ & $\begin{array}{l}960 \text { if throw of die is } 1-3 \\
25 \text { if throw of die is } 4-10\end{array}$ & $A$ & $B$ \\
\hline 4 & $\begin{array}{l}400 \text { if throw of die is } 1-4 \\
500 \text { if throw of die is } 5-10\end{array}$ & $\begin{array}{l}960 \text { if throw of die is } 1-4 \\
25 \text { if throw of die is } 5-10\end{array}$ & $A$ & B \\
\hline 5 & $\begin{array}{l}400 \text { if throw of die is } 1-5 \\
500 \text { if throw of die is } 6-10\end{array}$ & $\begin{array}{l}960 \text { if throw of die is } 1-5 \\
25 \text { if throw of die is } 6-10\end{array}$ & $A$ & $B$ \\
\hline 6 & $\begin{array}{l}400 \text { if throw of die is } 1-6 \\
500 \text { if throw of die is } 7-10\end{array}$ & $\begin{array}{l}960 \text { if throw of die is } 1-6 \\
25 \text { if throw of die is } 7-10\end{array}$ & $A$ & $B$ \\
\hline 7 & $\begin{array}{l}400 \text { if throw of die is } 1-7 \\
500 \text { if throw of die is } 8-10\end{array}$ & $\begin{array}{l}960 \text { if throw of die is } 1-7 \\
25 \text { if throw of die is } 8-10\end{array}$ & A & $B$ \\
\hline 8 & $\begin{array}{l}400 \text { if throw of die is } 1-8 \\
500 \text { if throw of die is } 9-10\end{array}$ & $\begin{array}{l}960 \text { if throw of die is } 1-8 \\
25 \text { if throw of die is } 9-10\end{array}$ & $A$ & $B$ \\
\hline 9 & $\begin{array}{l}400 \text { if throw of die is } 1-9 \\
500 \text { if throw of die is } 10\end{array}$ & $\begin{array}{l}960 \text { if throw of die is } 1-9 \\
25 \text { if throw of die is } 10\end{array}$ & A & $\mathrm{B}$ \\
\hline 10 & 400 if throw of die is $1-10$ & 960 if throw of die is $1-10$ & A & $\mathrm{B}$ \\
\hline
\end{tabular}

DECISION ROW CHOSEN BY FIRST THROW OF THE DIE:

THROW OF THE DIE TO DETERMINE PAYMENT:

EARNINGS TO THE OTHER PERSON: 
Your decision sheet shows ten decisions listed on the left. Notice that this decision sheet is quite similar to the one you used before, although the decision you are asked to make is quite different. Each decision is a paired choice between "Option A" and "Option B." You will make a choice on each row and record these in the final column. Contrary to the previous task, here your decisions will determine your own payoffs from this decision task.

Here is a ten-sided die that will be used to determine payoffs. The faces are numbered from 0 to 9 , and we will use the 0 face of the die to serve as 10 . Look at Decision 1 at the top. Option A pays 400 Rupees if the throw of the ten sided die is 1 , and it pays 500 Rupees if the throw is $2-10$. Option B yields 960 Rupees if the throw of the die is 1 , and it pays 25 Rupees if the throw is $2-10$.

The other Decisions are similar, except that as you move down the table, the chances of the higher payoff for each option increase. In fact, for Decision 10 in the bottom row, the die will not be needed since each option pays the highest payoff for sure, so your choice here is between 400 Rupees or 960 Rupees.

After you have made all of your choices, you will throw this die twice, once to select one of the ten decisions to be used, and a second time to determine what your payoff is for the option you chose, A or B, for the particular decision selected. Even though you will make ten decisions, only one of these will end up affecting your earnings, but you will not know in advance which decision will be used.

When you are finished, we will come around and hand out the instructions for the final task. After that we will let you perform the die rolls. We will then pay each of you in private and you will be free to go.

Please fill in the decision sheets now. Fill in the subject ID number that you can see on the yellow instruction pages you received inside the envelope. This goes in the top left corner of the decision sheet. 
ID: rR3

\begin{tabular}{|c|c|c|c|c|}
\hline Decision & Option A & Option B & \multicolumn{2}{|c|}{$\begin{array}{l}\text { Your Choice } \\
\text { (Circle A or B) }\end{array}$} \\
\hline 1 & $\begin{array}{l}400 \text { if throw of die is } 1 \\
500 \text { if throw of die is } 2-10\end{array}$ & $\begin{array}{l}960 \text { if throw of die is } 1 \\
25 \text { if throw of die is } 2-10\end{array}$ & $A$ & $\mathrm{~B}$ \\
\hline 2 & $\begin{array}{l}400 \text { if throw of die is } 1-2 \\
500 \text { if throw of die is } 3-10\end{array}$ & $\begin{array}{l}960 \text { if throw of die is } 1-2 \\
25 \text { if throw of die is } 3-10\end{array}$ & $A$ & $B$ \\
\hline 3 & $\begin{array}{l}400 \text { if throw of die is } 1-3 \\
500 \text { if throw of die is } 4-10\end{array}$ & $\begin{array}{l}960 \text { if throw of die is } 1-3 \\
25 \text { if throw of die is } 4-10\end{array}$ & $A$ & $B$ \\
\hline 4 & $\begin{array}{l}400 \text { if throw of die is } 1-4 \\
500 \text { if throw of die is } 5-10\end{array}$ & $\begin{array}{l}960 \text { if throw of die is } 1-4 \\
25 \text { if throw of die is } 5-10\end{array}$ & $A$ & B \\
\hline 5 & $\begin{array}{l}400 \text { if throw of die is } 1-5 \\
500 \text { if throw of die is } 6-10\end{array}$ & $\begin{array}{l}960 \text { if throw of die is } 1-5 \\
25 \text { if throw of die is } 6-10\end{array}$ & $A$ & $B$ \\
\hline 6 & $\begin{array}{l}400 \text { if throw of die is } 1-6 \\
500 \text { if throw of die is } 7-10\end{array}$ & $\begin{array}{l}960 \text { if throw of die is } 1-6 \\
25 \text { if throw of die is } 7-10\end{array}$ & $A$ & $B$ \\
\hline 7 & $\begin{array}{l}400 \text { if throw of die is } 1-7 \\
500 \text { if throw of die is } 8-10\end{array}$ & $\begin{array}{l}960 \text { if throw of die is } 1-7 \\
25 \text { if throw of die is } 8-10\end{array}$ & A & $B$ \\
\hline 8 & $\begin{array}{l}400 \text { if throw of die is } 1-8 \\
500 \text { if throw of die is } 9-10\end{array}$ & $\begin{array}{l}960 \text { if throw of die is } 1-8 \\
25 \text { if throw of die is } 9-10\end{array}$ & $A$ & $B$ \\
\hline 9 & $\begin{array}{l}400 \text { if throw of die is } 1-9 \\
500 \text { if throw of die is } 10\end{array}$ & $\begin{array}{l}960 \text { if throw of die is } 1-9 \\
25 \text { if throw of die is } 10\end{array}$ & A & $\mathrm{B}$ \\
\hline 10 & 400 if throw of die is $1-10$ & 960 if throw of die is $1-10$ & A & $\mathrm{B}$ \\
\hline
\end{tabular}

DECISION ROW CHOSEN BY FIRST THROW OF THE DIE:

THROW OF THE DIE TO DETERMINE PAYMENT:

YOUR EARNINGS: 
$\operatorname{Rr} 4$ Part 4 Decision Task

In this final task we want you to tell us how often you believe that option A was chosen by everyone else in this room. We want you to tell us your belief about the average number of times option A was chosen by everyone else. We will reward you for your accuracy. Remember, your choice does not count here. Please circle one number below in each column, to tell us what you believe:

Number of times option A

was picked on average

WHEN THEY PAYOFFS WERE

FOR THE PERSON

MAKING THE CHOICE

\section{Number of times option A was picked on average WHEN THE PAYOFFS WERE FOR A PERSON IN THE OTHER ROOM}

0

1

2

3

4

5

6

7

8

9

10
0

1

2

3

4

5

6

7

8

9

10

We will calculate the average for everyone else in the room, and round that to the nearest integer. If your estimate is exactly correct in one of the columns, you will receive 25 Rupees. If your estimates are exactly correct in both columns you will receive 50 Rupees. If it is 1 off, on either side, you will receive 10 Rupees for that column. If it is 1 off in both columns, you will receive10 Rupees for each of them. If it is more than 1 off in both columns you will not receive anything from this task. 
rR4

In this final task we want you to tell us how often you believe that option A was chosen by everyone else in this room. We want you to tell us your belief about the average number of times option A was chosen by everyone else. We will reward you for your accuracy. Remember, your choice does not count here. Please circle one number below in each column, to tell us what you believe:

Number of times option A

was picked on average

WHEN THE PAYOFFS WERE

FOR A PERSON IN THE

OTHER ROOM

0

1

2

3

4

5

6

7

8

9

10
Number of times option A

was picked on average

WHEN THE PAYOFFS WERE

FOR THE PERSON

MAKING THE CHOICE

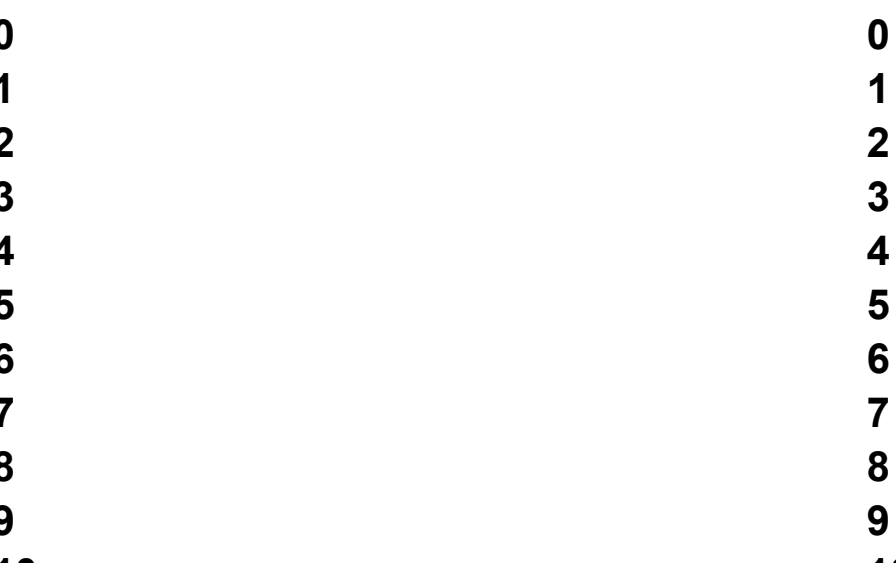

We will calculate the average for everyone else in the room, and round that to the nearest integer. If your estimate is exactly correct in one of the columns, you will receive 25 Rupees. If your estimates are exactly correct in both columns you will receive 50 Rupees. If it is 1 off, on either side, you will receive 10 Rupees for that column. If it is 1 off in both columns, you will receive10 Rupees for each of them. If it is more than 1 off in both columns you will not receive anything from this task. 
ID: $\operatorname{Rr}$

\section{YOUR INSTRUCTIONS}

We will wait for the monitor to arrive from the other room before we start reading these instructions. You may take out a book to read while we are waiting, but we ask that you do not talk to each other.

In today's experiment the earnings you will receive in addition to the participation fee of 25 Rupees is determined by decisions made by one other person in the other room and by the roll of a 10-sided die. The decisions made by the other person concerns a choice over two lotteries differing in the payoffs and risk. The person will pick one lottery, and this lottery will then be played out using the 10-sided die to determine how much additional earnings you will receive.

As we started the experiment you received your instructions packages in a random order. This ensures that the ID number that you have received, and that is listed in the top left corner of the instruction page, was given to you randomly. You may recall that everyone who came with us to this room received a red instruction package and everyone who remained in the other room received yellow ones. The two sets of instructions, the red and the yellow, have matching ID numbers. Thus, there is one person in the other room who has a yellow instruction package with the same ID number as yours. You will be matched with this person. We will not reveal to you who this person is, however, to guarantee that person's anonymity. This is the person who will make the choice between the lotteries that will determine your additional earnings.

You have received a copy of the instructions for the tasks given to the other people, that you may read through to understand how your earnings are determined. We ask that the monitor views one of these copies of the instructions to verify that these are indeed the same ones used in the other room. Do you have any questions at this point?

The monitor is also here to verify to the people in the other room that the instructions we give there are accurate. First, we need for the monitor to verify to the other room that we have __ people in this room, and that nobody has an ID number bigger than that. Please raise your hand if you do have an ID number that is bigger.

When all of the decisions in the other room has been made we will be able to tell you what additional earnings you will receive. When you have completed the survey questions that you will find in the instruction package, you may quietly read. We do ask that you not talk until everyone has completed their survey. We will tell you when everyone has completed their survey, and you can talk then if you want to.

Please answer the enclosed survey now. When you are finished please indicate to an experimenter who will then pick it up from you. 
ID: $r R$

\section{YOUR INSTRUCTIONS}

We will wait for the monitor to arrive from the other room before we start reading these instructions. You may take out a book to read while we are waiting, but we ask that you do not talk to each other.

In today's experiment the earnings you will receive in addition to the participation fee of 25 Rupees is determined by decisions made by one other person in the other room and by the roll of a 10-sided die. The decisions made by the other person concerns a choice over two lotteries differing in the payoffs and risk. The person will pick one lottery, and this lottery will then be played out using the 10-sided die to determine how much additional earnings you will receive.

As we started the experiment you received your instructions packages in a random order. This ensures that the ID number that you have received, and that is listed in the top left corner of the instruction page, was given to you randomly. You may recall that everyone who came with us to this room received a red instruction package and everyone who remained in the other room received yellow ones. The two sets of instructions, the red and the yellow, have matching ID numbers. Thus, there is one person in the other room who has a yellow instruction package with the same ID number as yours. You will be matched with this person. We will not reveal to you who this person is, however, to guarantee that person's anonymity. This is the person who will make the choice between the lotteries that will determine your additional earnings.

You have received a copy of the instructions for the tasks given to the other people, that you may read through to understand how your earnings are determined. We ask that the monitor views one of these copies of the instructions to verify that these are indeed the same ones used in the other room. Do you have any questions at this point?

The monitor is also here to verify to the people in the other room that the instructions we give there are accurate. First, we need for the monitor to verify to the other room that we have __ people in this room, and that nobody has an ID number bigger than that. Please raise your hand if you do have an ID number that is bigger.

When all of the decisions in the other room has been made we will be able to tell you what additional earnings you will receive. When you have completed the survey questions that you will find in the instruction package, you may quietly read. We do ask that you not talk until everyone has completed their survey. We will tell you when everyone has completed their survey, and you can talk then if you want to.

Please answer the enclosed survey now. When you are finished please indicate to an experimenter who will then pick it up from you. 


\section{Part 2: Some Questions About You}

ID: $\operatorname{Rr}$

In this survey most of the questions asked are descriptive. We will not be grading your answers and your responses are completely confidential. Please think carefully about each question and give your best answers.

1. What is your AGE? years

2. What is your sex? (Circle one number.)

$01 \quad$ Male

02 Female

3. Which of the following categories best describes you? (Circle one number.)

01 Hindu

02 Muslim

03 Christian

04 Jain

05 Sikh

06 Zoroastrian

07 Buddhist

08 Bahai

08 Scheduled Caste (SC)

09 Scheduled Tribe (ST)

10 Other Backward Class (OBC)

11 None of the above

12 Do not wish to answer

4. What was your undergraduate major? (Circle one number.)

$01 \quad$ Accounting

02 Economics

03 Finance

04 Business Administration, other than Accounting, Economics, or Finance

05 Education

$06 \quad$ Engineering

07 Health Professions

08 Public Affairs or Social Services

09 Biological Sciences

10 Math, Computer Sciences, or Physical Sciences

11 Social Sciences or History

12 Humanities

13 Psychology

14 Other Fields

5. What is your class standing? (Circle one number.)

01 First year Masters

02 Second year Masters

03 Doctoral student 
6. What was the highest level of education that your father (or male guardian) completed? (Circle one number)

01 Std. XII or less

02 Vocational Diploma

03 Bachelors Degree

04 Post Graduate Degree

7. What was the highest level of education that your mother (or female guardian) completed? (Circle one number)

01 Std. XII or less

02 Vocational Diploma

03 Bachelors Degree

04 Post Graduate Degree

8. Are you currently... (Circle one number.)

$01 \quad$ Single and never married?

02 Married?

03 Separated, divorced or widowed?

9. On a 4-point scale, what is your current CGPA? This CGPA should refer to all of your coursework, not just the current year. (Circle one number:)

01 Between 3.75 and 4.0 CGPA

02 Between 3.25 and 3.74 CGPA

03 Between 2.75 and 3.24 CGPA

04 Between 2.25 and 2.74 CGPA

05 Between 1.75 and 2.24 CGPA

06 Between 1.25 and 1.74 CGPA

07 Less than 1.25

08 Have not taken courses for which grades are given.

10. Please circle the category below that describes the total amount of gross (pre-tax) INCOME earned in 2004 by your parents. (Circle one number.)

01 Less than 1 lakh

02 Between 1 and 2.5 lakhs

03 Between 2.5 and 5 lakhs

04 Between 5 and 7.5 lakhs

05 Between 7.5 and 10 lakhs

06 Above 10 lakhs

11. Do you currently smoke cigarettes? (Circle one number.)

01 Yes

02 No

If yes, approximately how much do you smoke in one day? packs 


\section{RECEIPT}

I verify that I have participated in an economics experiment on and received the following earnings in compensation:

\section{Part 1:}

Part 3:

Part 4:

Fee:

25

Total:

Signature:

Print Name:

ID Number : (not your experiment ID) 